\title{
Inactivation of the CIC-DUX4 oncogene through P300/CBP inhibition, a therapeutic approach for CIC-DUX4 sarcoma
}

\author{
Darko Bosnakovski $\left(^{1,2,3 凶}{ }^{凶}\right.$, Elizabeth T. Ener (iD ${ }^{1,2}$, Mark S. Cooper ${ }^{4}$, Micah D. Gearhart ${ }^{5}{ }^{5}$, Kevin A. Knights ${ }^{4}$, Natalie C. Xu (D) $^{1,2}$, \\ Christian A. Palumbo (D) ${ }^{1,2}$, Erik A. Toso (iD) ${ }^{1,2}$, Graham P. Marsh (iD ${ }^{4}$, Hannah J. Maple (D) $^{4}$ and Michael Kyba (D) ${ }^{1,2}$
}

(c) The Author(s) 2021

CIC-DUX4 sarcoma (CDS) is a highly aggressive and metastatic small round type of predominantly pediatric sarcoma driven by a fusion oncoprotein comprising the transcriptional repressor Capicua (CIC) fused to the C-terminal transcriptional activation domain of DUX4. CDS rapidly develops resistance to chemotherapy, thus novel specific therapies are greatly needed. We demonstrate that CIC-DUX4 requires $\mathrm{P} 300 / C B P$ to induce histone $\mathrm{H} 3$ acetylation, activate its targets, and drive oncogenesis. We describe the synthetic route to a selective and highly potent P300/CBP inhibitor named iP300w and related stereoisomers, and find that iP300w efficiently suppresses CIC-DUX4 transcriptional activity and reverses CIC-DUX4 induced acetylation. iP300w is active at 100-fold lower concentrations than related stereoisomers or A-485. At low doses, iP300w shows specificity to CDS cancer cell lines, rapidly inducing cell cycle arrest and preventing growth of established CDS xenograft tumors when delivered in vivo. The effectiveness of iP300w to inactivate CIC-DUX4 highlights a promising therapeutic opportunity for CDS.

Oncogenesis (2021)10:68; https://doi.org/10.1038/s41389-021-00357-4

\section{INTRODUCTION}

A newly recognized commonly pediatric subtype of undifferentiated round cell sarcoma that is driven by fusion between the cell cycle regulator and transcriptional repressor, capicua $(\mathrm{CIC})$, and the transcriptional activator, DUX4, has been identified based on its histology, clinical differences, and aggressiveness [1-8]. CIC-DUX4 sarcoma (CDS) occurs predominantly in children and young adults and usually develops in somatic soft tissues $[4,5,9,10]$. Patients with CDS show an aggressive clinical course with a high metastatic rate and quickly develop resistance to chemotherapy. The median survival is less than 2 years $[6,9,11]$. CDS at the molecular level is poorly understood and so far, all of the treatment efforts have poor and unsatisfactory outcomes.

The CIC-DUX4 fusion is the product of a translocation between the Capicua Transcriptional Repressor (CIC) on chromosome 19 and DUX4 on chromosome $4(4 ; 19)(q 35 ; q 13)$, or on rare occasions with DUX4 from chromosome $10(10 ; 19)(q 26 ; q 13)[1,7]$. DUX4 is the double homeobox transcription factor gene embedded in each D4Z4 macrosatellite repeat located at both $4 q 35$ and $10 q 26.3$ $[12,13]$. The CIC-DUX4 oncoprotein contains the majority of the $\mathrm{N}$-terminal part of $\mathrm{CIC}$, which encompasses its DNA binding domain, and a small C-terminal part of DUX4 that has strong transcriptional activation properties $[8,14,15]$. The acquisition of the DUX4 C-terminus transforms $\mathrm{ClC}$ from a transcriptional repressor into an activator [8]. Crucial cell cycle genes, as well as genes involved in driving metastasis previously repressed by $\mathrm{CIC}$, are expressed at high levels, driving uncontrolled cell division and malignant transformation $[8,16,17]$.
DUX4 is known for its involvment in early embryogenesis [18-20] and facioscapulohumeral muscular dystrophy (FSHD) [21-23]. We have shown that the C-terminus of DUX4 recruits $\mathrm{P} 300 / \mathrm{CBP}$ and induces both local histone (H3) acetylation and total nuclear histone $\mathrm{H} 3$ hyperacetylation [15]. Deletion of the C-terminus of DUX4 eliminates induced H3 acetylation and target gene expression [14, 15, 24]. Similar effects were achieved by specific P300 inhibition in cells expressing DUX4 [25].

Because CIC-DUX4 acquires the p300-interacting activation domain of DUX4, we hypothesized that its transcriptional activation potential, and thus the oncogenicity of CIC-DUX4, would require $\mathrm{P} 300$ or its homolog, CBP. Recently, a new class of histone acetyltransferase inhibitor with high selectivity for P300 and CBP has been described, and two compounds, A-485, and iP300w, have been shown to inhibit P300 and CBP both in vitro and in vivo $[25,26]$, with iP300w having the ability to reverse gene expression changes caused by DUX4. If this hypothesis is correct, iP300w should potently counteract the CIC-DUX4 gene expression program and might be a particularly effective therapy for CDS. In this study, we confirm this hypothesis, demonstrating that CIC-DUX4 requires P300/CBP for its activity. We also demonstrate that CIC-DUX4 induces a global increase in $\mathrm{H} 3$ acetylation, like DUX4, which is reversible with iP300w treatment. We find that CIC-DUX4 activity is potently blocked by $\mathrm{iP} 300 \mathrm{w}$, and that this compound has potent activity against CDS cell lines in vitro, and in an in vivo cancer xenograft assay.

\footnotetext{
${ }^{1}$ Lillehei Heart Institute, Minneapolis, USA. ${ }^{2}$ Department of Pediatrics, University of Minnesota, Minneapolis, MN 55455, USA. ${ }^{3}$ Faculty of Medical Sciences, University Goce Delchev - Shtip, Shtip 2000, Republic of North Macedonia. ${ }^{4}$ Bio-Techne (Tocris), The Watkins Building, Atlantic Road, Avonmouth, Bristol, UK. ${ }^{5}$ Department of Genetics, Cell Biology and

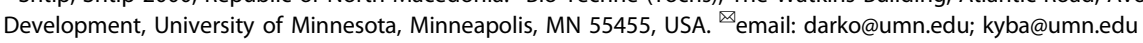

Received: 21 May 2021 Revised: 13 September 2021 Accepted: 23 September 2021

Published online: 12 October 2021 
A

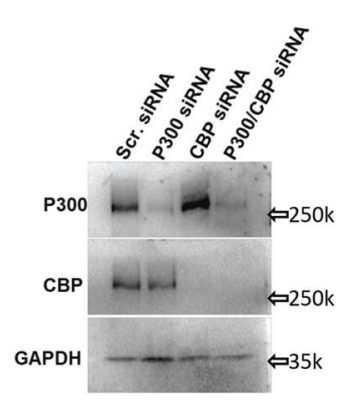

D

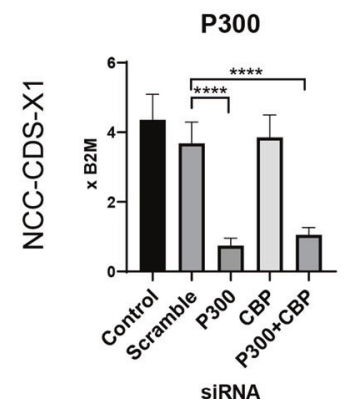

B

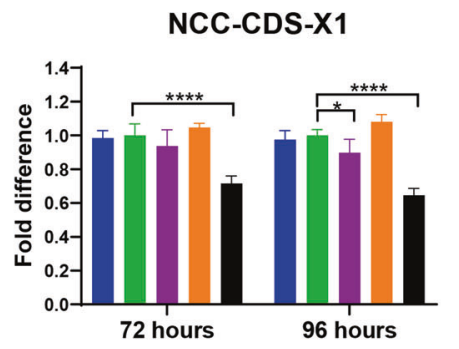

C

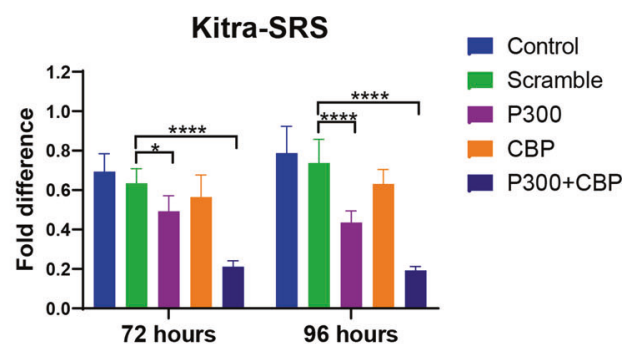

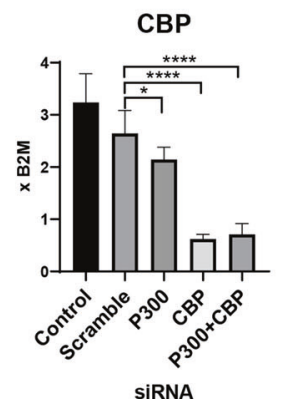
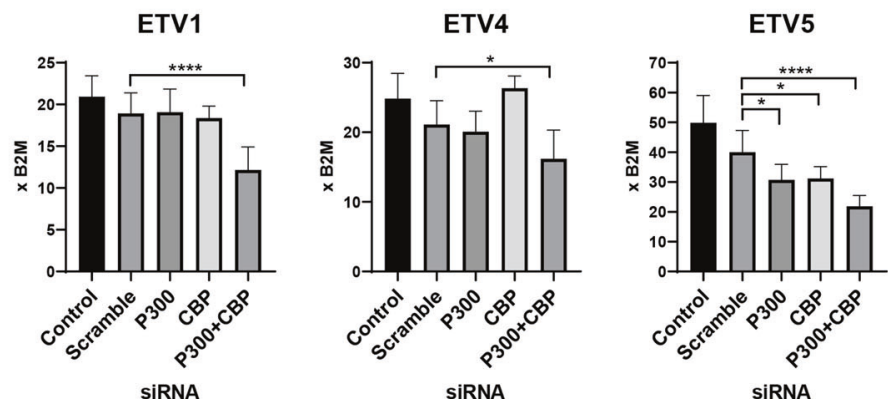

Fig. 1 P300/CBP is required for CIC-DUX4 activity. A Western blots for P300 and CBP in NCC-CDS-X1 cells after $96 \mathrm{~h}$ transfection with siRNAs for P300 and CBP. B ATP assay for cell viability of NCC-CDS-X1 at 72 and $96 \mathrm{~h}$ of post-transfection with P300 and/or CBP siRNA. Non-treated cells and cells transfected with non-targeting siRNA (scramble) were used as negative controls. Data are presented as mean \pm SEM; ${ }^{*} p<0.05$, ${ }^{* * *} p<0.001$ by one-way ANOVA. Results are presented as relative expression to control $(n=4)$. C ATP viability assay in the Kitra-SRS cell line in the same experimental conditions as explained in "B". Data are presented as mean $\pm \mathrm{SEM}$; ${ }^{* * *} p<0.0001$, by two-way ANOVA. Results are presented as expression relative to control $(n=4)$. D RT-qPCR for P300, CBP, and CIC-DUX4 target genes in NCC-CDS-X1. Analyses were performed $48 \mathrm{~h}$ post-transfection with P300 and/or CBP siRNA. Data are presented as mean $\pm \mathrm{SEM} ;{ }^{*} p<0.05,{ }^{* *} p<0.01,{ }^{* * *} p<0.001$ by oneway ANOVA. Results are presented as expression relative to $B 2 M(n=3)$.

\section{RESULTS}

\section{CIC-DUX4 acts through P300/CBP}

We previously showed that the C-terminus of DUX4 interacts with P300 and induces both DUX4 target locus-specific acetylation as well as a global elevation of acetylation on $\mathrm{H} 3 \mathrm{~K} 18$ and $\mathrm{H} 3 \mathrm{~K} 27$ $[15,25]$. Thus, it is likely that CIC-DUX4 also requires P300/CBP for activation of its targets. To test this hypothesis, we knocked down P300 and CBP in two cell lines, NCC-CDS-X1 and Kitra-SRS, derived from independent CDS tumors $[27,28]$ and evaluated cell viability and CIC-DUX4 target gene expression in these cells. The efficiency of the knockdown was confirmed by western blot (Fig. 1A). Cotransfection with P300 and CBP siRNA resulted in significant reductions of cell viability in both cell lines at 72 and $96 \mathrm{~h}$ of posttransfection (Fig. 1B, C). Notably, a slight but still significant decrease in cell proliferation was detected in the cells in which only P300 was targeted. The knockdown also resulted in reductions of the key CIC-DUX4 target genes, ETV1, 4, and 5 (Fig. 1D and Supplementary Fig. 1). ETV4 is a well-established CIC-DUX4 target and cancer metastatic driver that has been used to distinguish CDS from the other Ewing sarcomas [8, 10, 16, 29]. Thus, we conclude that CIC-DUX4 transcriptional activity and with that, CDS proliferation and/or survival, depends on P300/CBP.

\section{Synthesis and stereochemical evaluation of iP300w, a potent P300/CBP inhibitor}

The first potent and highly selective inhibitor of the HAT domain of P300 and CBP to be reported was A-485 (Fig. 2A) [26], a competitive binder for the acetyl co-A site of P300. Several structurally related compounds from the same series have recently been described to have P300 inhibitory activity $[25,30-32]$. One of these, iP300, was shown to have activity residing in a single diastereomer with undefined stereochemistry, named 'iP300w' (Fig. 2A) [25]. A second undefined diastereomer (Comp 13) exhibited substantially reduced activity [25]. Given the structural similarities with A-485, iP300w might reasonably be assumed to share the same stereochemical configuration at both the central spirocyclic core and adjacent to the terminal trifluoromethyl moiety $((R)$ and $(S)$ respectively in A-485). Contrary to this assumption, the stereochemical assignment from the original patent (WO2016044770) provides the spirocyclic core of iP300w as $(S)$, and it has been further illustrated that the preferred stereochemistry at this center for such spiro-hydantoin compounds is surprisingly opposite to the comparable spirooxazolidinediones [30, 32].

We synthesized and isolated four diastereomers of iP300 according to the route shown (Fig. 2B). From commercially available 5-bromoindan-1-one, a Bucherer-Bergs reaction facilitated elaboration to the hydantoin (1), with subsequent oxonemediated benzylic oxidation affording (2). Alkylation with enantiomerically pure bromide (4) gave rise to a mixture of (6) and (7), which were separated and independently advanced to the end of the synthesis. Suzuki-Miyaura coupling afforded (8) and (9), with the final stereocenter being installed by a two-stage reduction and fluorination sequence.

Compound (12) co-eluted by HPLC with an authentic sample of iP300w from the original study (Bosnakovski et al. [25], while compound (14) co-eluted with an authentic sample of iP300v. The absolute stereochemistry of (14) (iP300v) was determined by single crystal X-ray diffraction as being $(R)$ at the spirocycle and $(S)$ at the fluoro-substituent (Supplementary Fig. 2A). Furthermore, analysis of precursor (6) (Supplementary Fig. 2B) by single crystal $\mathrm{X}$-ray diffraction revealed the spirocyclic core being in the $(S)$ configuration, unequivocally confirming the absolute stereochemical arrangement of the active diastereomer (12) (iP300w). 
A

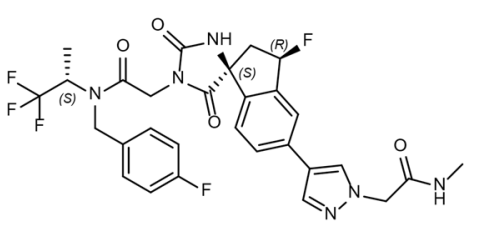

iP300w (12)<smiles>CNC(=O)Nc1ccc2c(c1)CCC21CC(=O)N(CC(=O)N(Cc2ccc(F)cc2)C(C)C)C1=O</smiles>

A-485
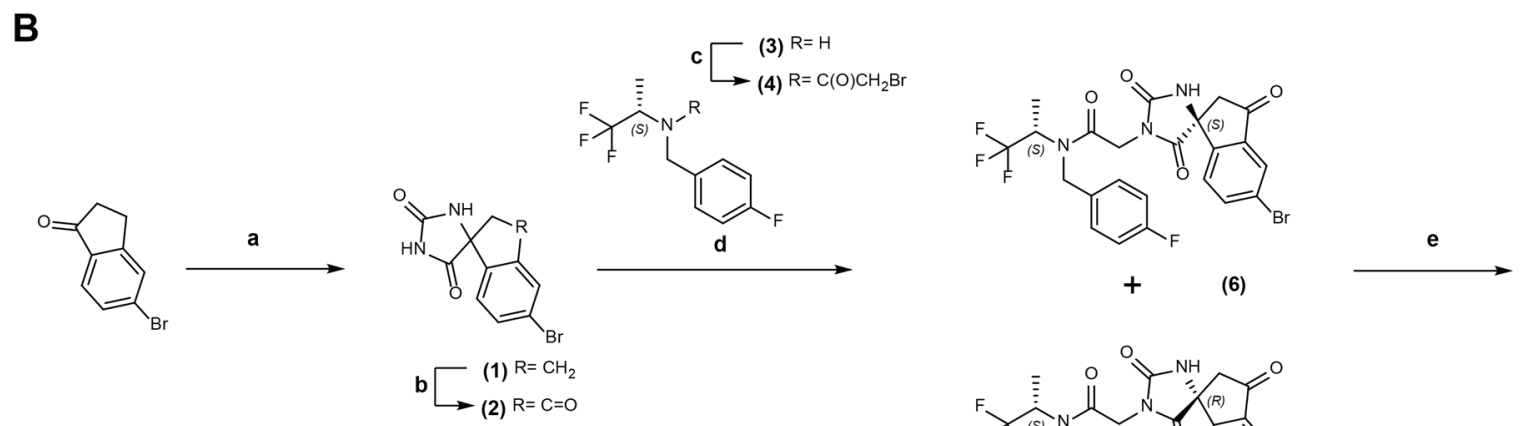<smiles>CNC(=O)Cn1cc(-c2ccc3c(c2)C(=O)C[C@]32NC(=O)N(CC(=O)N(Cc3ccc(F)cc3)[C@@H](C)C(F)(F)F)C2=O)cn1</smiles>

(8)<smiles>C[C@@H](N(Cc1ccc(F)cc1)C(=O)N1C(=O)N[C@]2(CC(=O)c3cc(Br)ccc32)C1=O)C(F)(F)F</smiles>

(7)<smiles>CNC(=O)Cn1cc(-c2ccc3c(c2)C(=O)C[C@]32NC(=O)N(CC(=O)N(Cc3ccc(F)cc3)[C@@H](C)C(F)(F)F)C2=O)cn1</smiles>
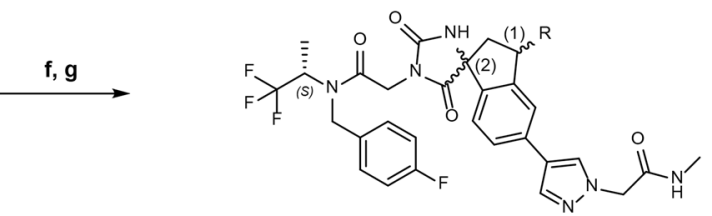

$(10,11) \mathrm{R}=\mathrm{OH}$

$(12,13,14,15) R=F$

\begin{tabular}{|c|c|c|}
\hline Compound & Stereochemistry (1) & Stereochemistry (2) \\
\hline iP300w (12) & $(R)$ & $(S)$ \\
\hline $\begin{array}{c}(S, S, S) \text {-minor } \\
\text { diastereomer (13) }\end{array}$ & $(S)$ & $(S)$ \\
\hline iP300v (14) & $(S)$ & $(R)$ \\
\hline $\begin{array}{c}(R, R, S)-\text {-minor } \\
\text { diastereomer (15) }\end{array}$ & $(R)$ & $(R)$ \\
\hline
\end{tabular}

Fig. 2 Synthesis and structure of iP300w and stereoisomers. A Structures of iP300w and A-485. B Synthesis pathway, reagents and conditions: a $\mathrm{KCN},(\mathrm{NH} 4) 2 \mathrm{CO} 3, \mathrm{EtOH}, \mathrm{H}_{2} \mathrm{O}, 70^{\circ} \mathrm{C}$; b sodium 2-iodobenzenesulfonic acid, $\left.\left(\mathrm{CH}_{3} \mathrm{CH}_{2} \mathrm{CH}_{2} \mathrm{CH}_{2}\right) 4 \mathrm{~N}(\mathrm{HSO})_{4}\right), \mathrm{OxOne}, \mathrm{MeCN}, 65^{\circ} \mathrm{C}$; c bromoacetyl bromide, DCM, RT; d K2CO3, DMF, $5{ }^{\circ} \mathrm{C}$, followed by preparative chromatography; e N-methyl-2-(4-(4,4,5,5-tetramethyl-1,3,2dioxaborolan-2-yl)-1H-pyrazol-1-yl)acetamide, $\mathrm{Pd}(\mathrm{dppf}) \mathrm{Cl} 2 . \mathrm{CH} 2 \mathrm{Cl} 2, \mathrm{~K} 2 \mathrm{CO} 3,1$,4-dioxane, $\mathrm{H}_{2} \mathrm{O}, 95^{\circ} \mathrm{C} ; \mathbf{f} \mathrm{NaBH} 4, \mathrm{THF}, \mathrm{MeOH}, 0^{\circ} \mathrm{C} ; \mathbf{g} \mathrm{DAST}, \mathrm{DCM}$, $-70^{\circ} \mathrm{C}$.

\section{iP300w and related compounds decrease CIC-DUX4 sarcoma cell viability}

We evaluated the activity of the various iP300w stereoisomers against NCC-CDS-X1 cells. Cultures were treated with serial dilutions, ranging from 0.003 to $3.0 \mu \mathrm{M}$, for up to $96 \mathrm{~h}$. In cells treated with iP300w, a significant decrease in cell viability was evident at the lowest concentration $(0.003 \mu \mathrm{M})$ at 48 and $96 \mathrm{~h}$ (Fig. 3A). The effect was dose-dependent and time-dependent. In addition to iP300w, two compounds, stereoisomer Comp 13, and related compound A485 , also showed activity, but at the early time point ( $48 \mathrm{~h}$ ) only at the highest concentrations. We calculated $\mathrm{IC}_{50}$ values and concluded that Comp 13 and A-485 are approximately 20-fold less potent than iP300w. (Fig. 3B and Supplementary Fig. 3).

Next, we analyzed the effect of the stereoisomers on CIC-DUX4 and its target genes in cells cultured with the compounds for $24 \mathrm{~h}$. Except for A-485 at the highest concentration $(0.3 \mu \mathrm{M})$, none of the compounds significantly affected CIC-DUX4 expression
(Fig. 3C). We detected significant downregulation of all three direct targets, ETV1, 4, and 5 in the group treated with iP300w (Fig. 3C). Comp 13 and A-485 at the highest concentration also had a notable effect on ETV4. Cell cycle genes, including a known CIC-DUX4 target CCNE-CDK2 complex [16], were also affected by iP300w (Fig. 3C). Taken together, based on the cell viability assay and the gene expression analyses, we identified iP300w as the most potent inhibitor of CIC-DUX4.

\section{iP300w inhibits CIC-DUX4 sarcoma cell line proliferation}

To more rigorously evaluate the consequences of iP300w treatment of CDS cells, we monitored its effects on both monolayer as well as 3D spheroid cultures and in both CDS cell lines. Inhibition of proliferation was morphologically apparent as early as $24 \mathrm{~h}$ after iP300w treatment (not shown) and progressed with time (Fig. 4A). Using the cell viability assay, we determined that $0.003 \mu \mathrm{M}$ was the lowest effective concentration on day 2 in 
A

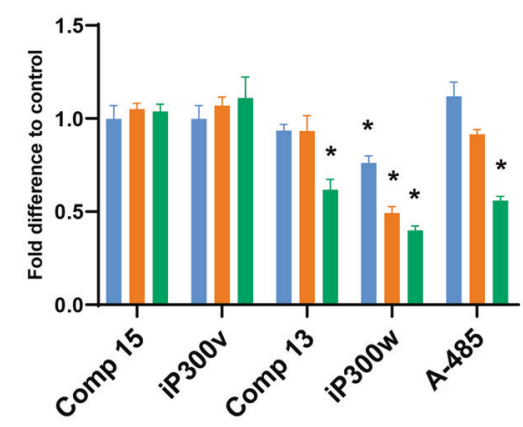

ATP- 96 hours

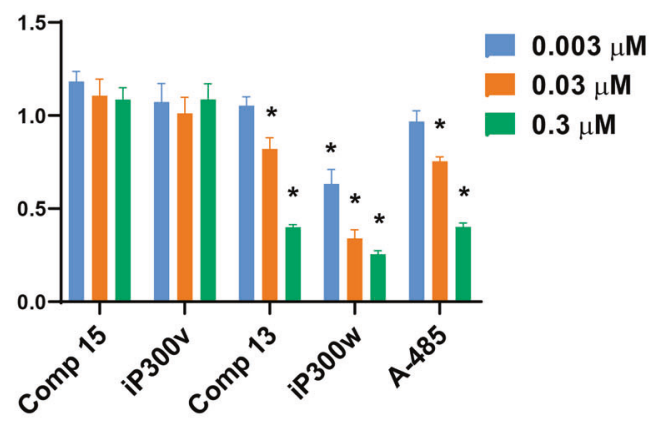

B
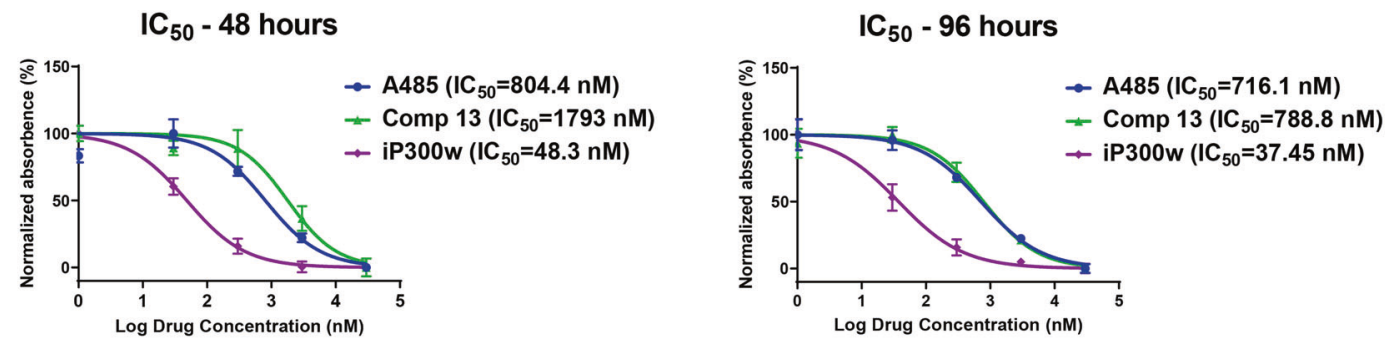

C
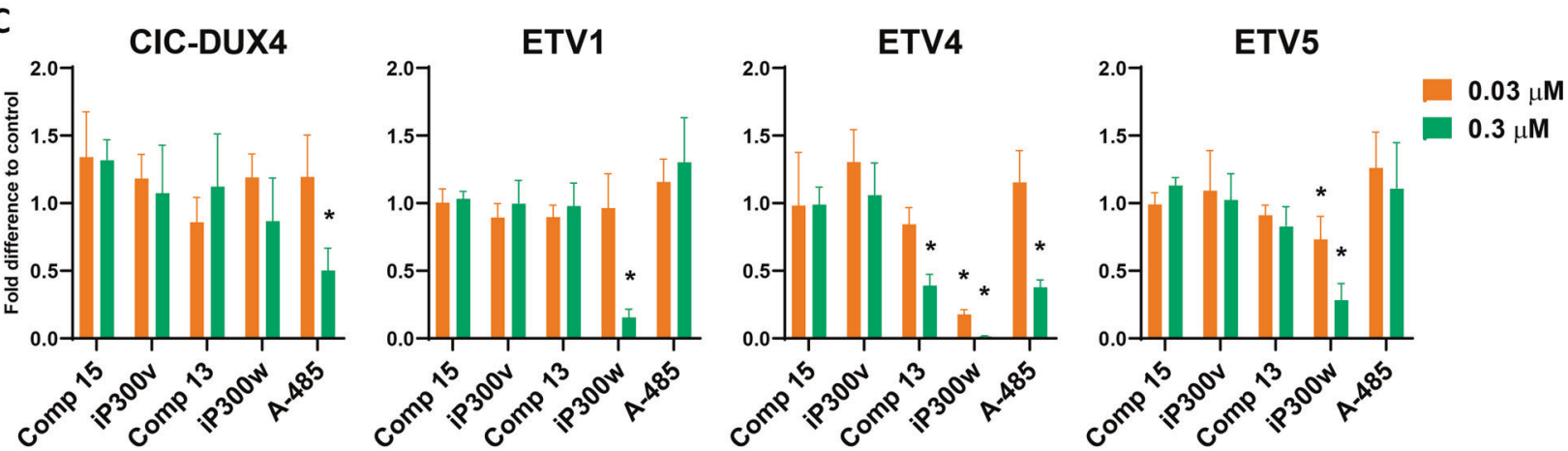

CCNE1
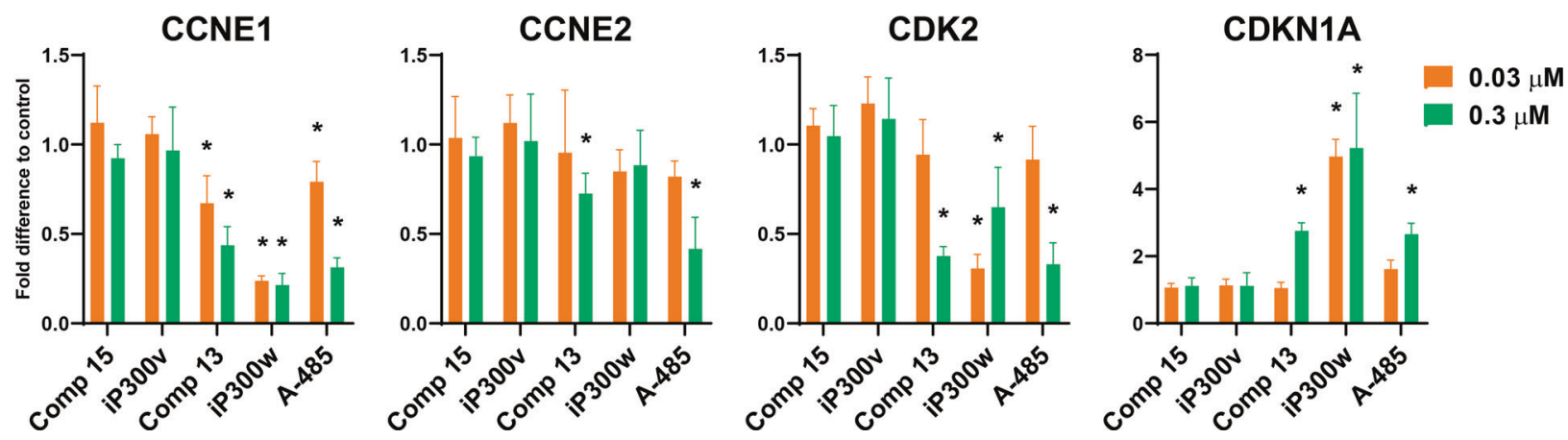

Fig. 3 Effect of iP300w stereoisomers on CIC-DUX4 sarcoma cell line viability. A ATP viability assays at 48 and $96 \mathrm{~h}$ of treatment of NCCCDS-X1 cells with different concentrations of iP300w stereoisomers and A-485. B IC 50 values of A-485, Comp 13 and iP300w in NCC-CDS-X1 cells at 48 and $98 \mathrm{~h}$ of treatment. C RT-qPCR for CIC-DUX4 target genes in NCC-CDS-X1 cells after $24 \mathrm{~h}$ treatment with 0.03 and $0.3 \mu \mathrm{M}$ iP300w stereoisomers and A-485. Data is presented as mean $\pm \mathrm{SEM}$; ${ }^{*} p<0.05$, by two-way ANOVA. Results are presented as expression relative to control $(n=3)$.

both lines (Fig. 4B). The dose- and time-responsive inhibitory effect of iP300w on CDS cell spheroid formation and growth was also evident (Fig. 4C and Supplementary Fig. 4). Two independent approaches, Ki-67 staining and EdU incorporation revealed that iP300w treatment arrested proliferation of most cells. An almost complete absence of Ki-67 staining was observed in both NCC-CDS-X1 and Kitra-SRS cells at 24 (Fig. 4D) hours, and progressive reductions were obtained with EdU labeling until virtually no cells were labeled at $48 \mathrm{~h}$ (Fig. 4E, F). We also tested CDS cells for the effects of pulses of iP300w exposure. Interestingly, a $4 \mathrm{~h}$ pulse significantly reduced proliferation rate measured $20 \mathrm{~h}$ later (Fig. 4G, H). The effect was even more dramatic in the cells treated for $24 \mathrm{~h}$, as they were not able to restore the cell cycle $48 \mathrm{~h}$ after the pulse (Fig. 4G, H). 
We treated pancreatic and colorectal cancer cell lines with iP300w to further distinguish its specificity to CDS from general cytotoxicity. p300/CBP have been correlated with the invasive and migratory properties of pancreatic and colorectal cancers [33, 34]. Notably, we did not observe any significant effect on cell viability in the tested cell lines (Supplementary Fig. 5A, B). However, we did

A
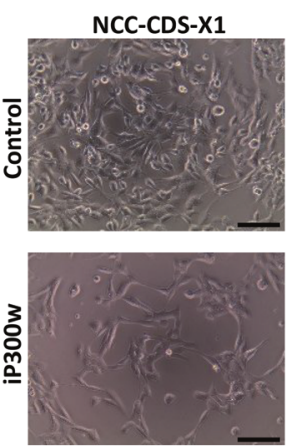

D
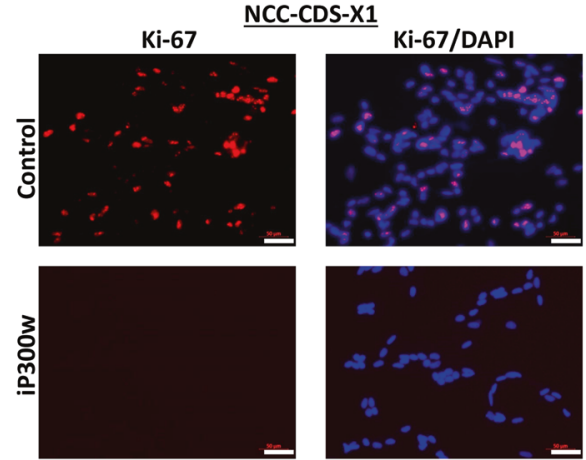

Kitra-SRS
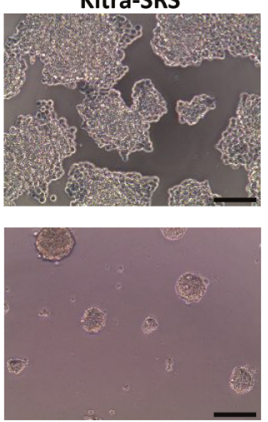

notice a mild suppression of proliferation of iP300w in LHCN-M2 cells at a concentration of $0.3 \mu \mathrm{M}$ or higher after 3 days of treatment (Supplementary Fig. 5C).

We evaluated the effectiveness of iP300w to suppress CDS tumor growth in vivo. NCC-CDS-X1 cells were used to generate subcutaneous xenograft tumors in immunodeficient NSG mice
B

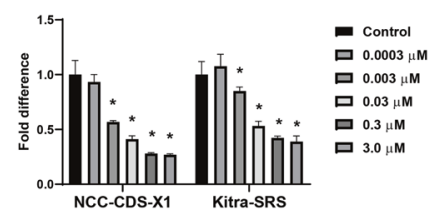

C
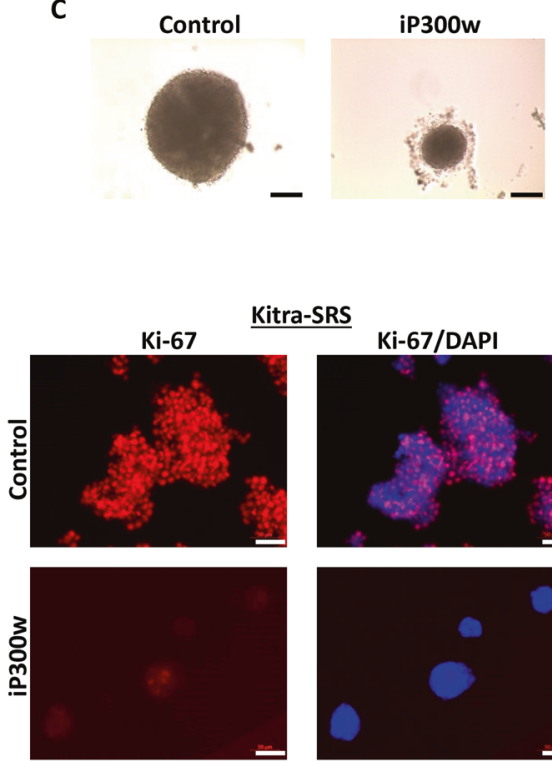

Kitra-SRS
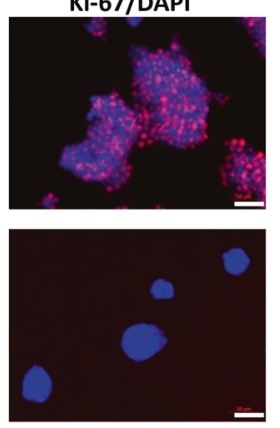

$\mathbf{F}$

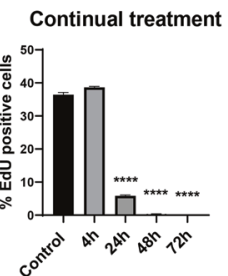

E

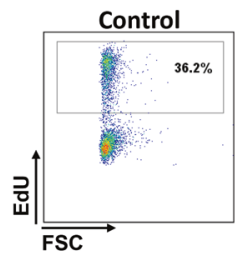

G

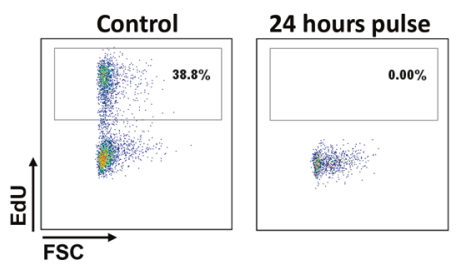

H

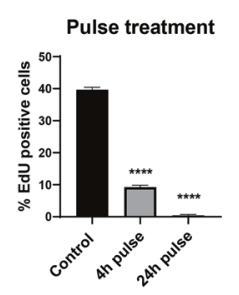

I
J

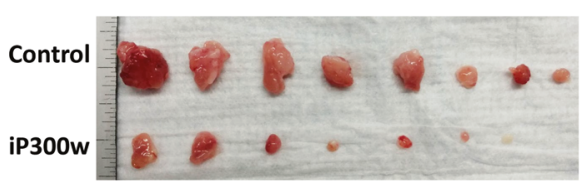

K

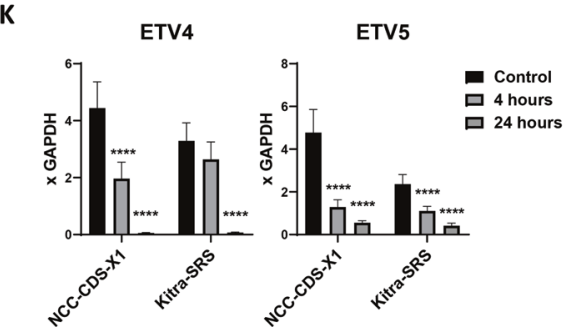


Fig. 4 iP300w suppresses CIC-DUX4 sarcoma cell proliferation in vivo and in vitro. A Morphology of NCC-CDS-X1 and Kitra-SRS cell cultures at $48 \mathrm{~h}$ of treatment with iP300w $(0.3 \mu \mathrm{M})$. Scale bar, $50 \mu \mathrm{m}$. B ATP assay for cell viability at $48 \mathrm{~h}$ of treatment with a serial dilution of iP300w. C NCC-CDS-X1 spheroid morphology after 4 days of treatment with iP300w (0.3 $\mu \mathrm{M})$. Scale bar, $50 \mu \mathrm{m}$. D Immunofluorescence for Ki-67 in NCCCDS-X1 and Kitra-SRS cells treated for $24 \mathrm{~h}$ with iP300w $(0.3 \mu \mathrm{M})$. Scale bar, $50 \mu \mathrm{m}$. E Representative FACS analyses for EdU incorporation in NCC-CDS-X1 cells. Cells were treated with $0.3 \mu \mathrm{M}$ iP300 w for 4,24 , and $48 \mathrm{~h}$. In the last $4 \mathrm{~h}$ of treatment proliferating cells were labeled with EdU $(10 \mu \mathrm{M})$. F Summary of the FACS analyses presented in "E". Data are presented as mean \pm SEM; * $p<0.05$, by one-way ANOVA. Results are presented as expression relative to control $(n=3)$. G Representative FACS analyses for EdU incorporation in NCC-CDS-X1 cells after a pulse of iP300w $(0.3 \mu \mathrm{M})$. Cells were incubated for different periods with iP300w $(0.3 \mu \mathrm{M})$ and analyzed by FACS $24 \mathrm{~h}$ later. In the last $4 \mathrm{~h}$ of the experiment, the cells were incubated with EdU. H Summary of FACS analyses presented in "G". I Size of the NCC-CDS-X1 xenograft tumors in control and treated mice over 12 days. Mice $(n=8)$ were treated $1.4 \mathrm{mg} / \mathrm{kg}$ iP300w twice daily. J Gross morphology of dissected tumors at the endpoint of the experiment (day 12) presented in "I." K RT-qPCR for ETV4 and ETV5 in NCC-CDS-X1 and Kitra-SRS cell lines after 4 and $24 \mathrm{~h}$ of treatment with $0.3 \mu \mathrm{M}$ iP300w. Data are presented as mean $\pm \mathrm{SEM} ;{ }^{*} p<0.05,{ }^{* *} p<0.01,{ }^{* * *} p<0.001$ by one-way ANOVA. Results are presented as expression relative to $G A P D H(n=3)$.

$(n=8)$. When tumors were palpable (day 9) iP300w injections $(1.4 \mathrm{mg} / \mathrm{kg}$ b.i.d.) were initiated and the progression of tumor growth was monitored. While tumor growth was evident in the control mice, growth was halted $(5 / 8)$ or significantly diminished $(3 / 8)$ in the treated mice (Fig. $4 \mathrm{l}, \mathrm{J}$ ).

Finally, we confirmed that iP300w effectively suppresses transcription of CIC-DUX4 direct target genes ETV4 and ETV5 in both NCC-CDS-X1 and Kitra-SRS cell lines at $24 \mathrm{~h}$ of treatment (Fig. 4K).

\section{iP300w suppresses the CIC-DUX4 induced transcriptome}

We next investigated global transcriptional profiles of NCCCDS-X1 cells treated with iP300w. RNA-seq performed after treatment with iP300w identified 1182 downregulated and 872 upregulated genes $4 \mathrm{~h}$ post-treatment and 2042 downregulated and 1658 upregulated genes $24 \mathrm{~h}$ post-treatment (2-fold or greater change in gene expression ( $\log 2 \mathrm{FC}>1$ or $<-1$ ), Benjamini-Hochberg adjusted $p$-value $<0.05$, mean counts across samples $>10$ and FPKM in the control or iP300wtreated sample $>2.5$ ). Among these differentially expressed genes, 170 and 244 were changed by more than 10 -fold at $4 \mathrm{~h}$ and $24 \mathrm{~h}$, respectively (Fig. 5A and Supplementary Table 1). As numerous genes are dependent on P300 acetyltransferase activity, we were particularly interested in genes that are known to be direct targets of CIC-DUX4. Using the set of 165 CIC-DUX4 targets identified by Okimoto et al. [16], we found numerous key transformation-regulatory genes, including ETV1, ETV4, and CCNE1, to be significantly downregulated within $4 \mathrm{~h}$ of iP300w treatment, and the vast majority of $\mathrm{CIC}$ DUX4 targets to be downregulated by $24 \mathrm{~h}$ of iP300w treatment (Fig. 5B). This contrasts with the global background of gene expression changes, which were divided among upregulation and downregulation, and argues that iP300w has a predominately antagonistic effect on the genes induced by the oncogenic CIC-DUX4 transformation. Further supporting this notion is that one of the rare upregulated genes was p21 (CDKN1A, upregulated in the $24 \mathrm{~h}$ dataset).

Because iP300w treatment affected many genes not previously described as CIC-DUX4 targets, we performed enrichment analysis with Kyoto Encyclopedia of Genes and Genomes (KEGG) pathways with the upregulated and downregulated genes (Fig. 5C). Several pathways related to cancer, as well as signaling pathways frequently misregulated in cancer, were enriched among the genes downregulated at $4 \mathrm{~h}$, including the TGF-beta, WNT, and MAPK signaling pathways. By $24 \mathrm{~h}$ the enriched pathways for downregulated genes also included ribosome biogenesis, DNA replication, and cell cycle consistent with previously observed inhibition of cell cycle. A similar set of pathways was enriched among the downregulated genes previously identified as $\mathrm{CIC}$ DUX4 targets. We identified a set of $30 \mathrm{iP300w}$ responsive genes among the CIC-DUX4 targets that contribute to these pathways including ETV1, ETV4, ETV5, CCNE1, and TGFB3 as central to the transformation by CIC-DUX4 that can be reversed by inhibiting P300/CBP (Supplementary Fig. 6).

\section{CIC-DUX4 induces global $\mathrm{H3}$ acetylation, which is reversed by iP300w}

Finally, we have previously shown that DUX4 expression leads to a global increase of $\mathrm{H} 3 \mathrm{~K} 18$ and $\mathrm{H} 3 \mathrm{~K} 27$ acetylation, through a mechanism that is as yet undetermined, but dependent on P300 activity [25]. We wondered whether CIC-DUX4, which bears the P300 interaction domain of DUX4, would have this same activity. We therefore generated different sets of cell lines that constitutively overexpress CIC-DUX4 (Fig. 6A and Supplementary Fig. 7A, B). We used multiple cell lines, of both mouse and human origin, to exclude cell-type-specific effects. In each cell line, overexpression of CIC-DUX4 resulted in induction of ETV1, 4, and 5, which was reversible with iP300w treatment (Fig. 6B and Supplementary Fig. 7A, B) indicating the relevant functionality of CIC-DUX4 expressed in each line, and further demonstrating the effectiveness of iP300w to interfere with the CIC-DUX4/ETV4 transformation axis. We then investigated the global acetylation status of H3K18 and H3K27 after CIC-DUX4 induction. It is well accepted that acetylation of both $\mathrm{H} 3$ lysines is facilitated by P300/CBP and that these modifications mark active enhancers [35-37], however whether and how an increase in the global balance of acetylated to nonacetylated $\mathrm{H} 3$ would lead to elevated global transcription, and whether this is relevant to transformation is unclear. As we previously observed with DUX4, expression of CIC-DUX4 resulted in dramatically increased global acetylation on both lysines in all of the analyzed cell lines (Fig. 6C and Supplementary Fig. 7C). This acetylation was dependent on P300/CBP, as it was abolished in the presence of iP300w. Importantly, we also demonstrated that iP300w reduces global H3K18 and H3K27 acetylation in NCC-CDS$\mathrm{X} 1$ and Kitra-SRS CDS cell lines (Fig. 6D). Taken together, this data shows that iP300w prevents and reverses CIC-DUX4-induced H3K18 and H3K27 acetylation.

\section{DISCUSSION}

In this study, we show that CIC-DUX4, which bears the P300interacting DUX4 C-terminus [15], activates transcription in a way that is mechanistically related to DUX4, namely, being critically dependent on P300/CBP histone acetyltransferase activity [25]. P300 and CBP are histone acetyltransferases $[38,39]$ that regulate gene expression in a wide range of cellular processes, including proliferation, differentiation, response to DNA damage, senescence, and apoptosis [33, 40]. Furthermore, they interact with multiple oncogenes/tumor suppressors and are essential for their activity and carcinogenesis [41-44]. Here, we show that the oncogenic mechanism of CIC-DUX4, which involves both deregulation of cell cycle through upregulation of genes such as CCNE1 as well as induction of invasion and metastasis potential through upregulation of ETV4 and related Ets-family genes [16], is critically dependent on P300/CBP. Knockdown of both histone acetyltransferases P300 and CBP in CDS cell lines results in the prevention of CIC-DUX4 target gene expression leading to cell cycle arrest. Thus, we identify disruption of the CIC-DUX4/P300/CBP axis as a potential druggable approach for CDS treatment. 
A
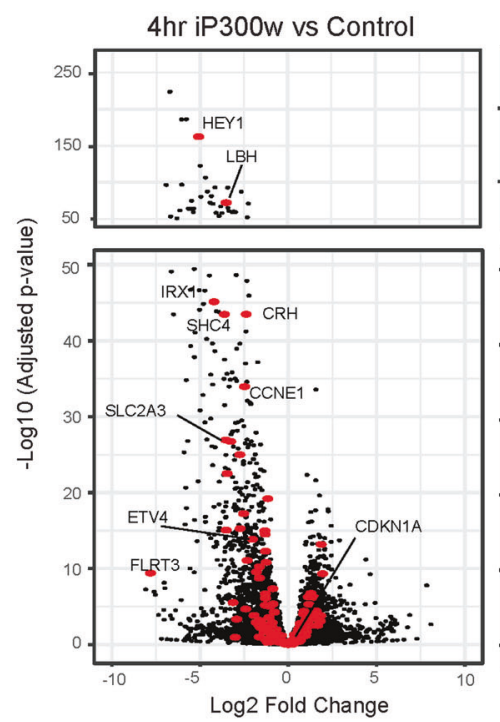

- CIC-DUX4 Target Genes (Okimoto et al, 2019)

C Enriched KEGG Pathways
Genes Differentially Expressed at 4hrs

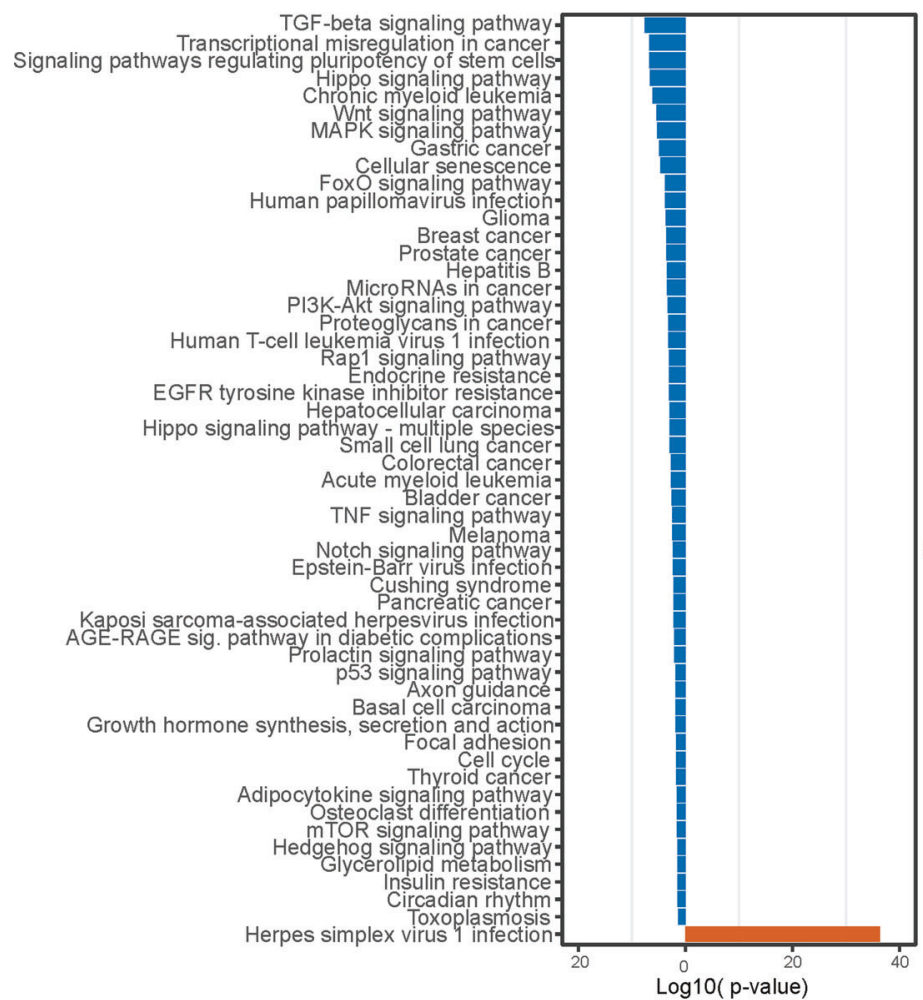

Down Regulated Genes
B

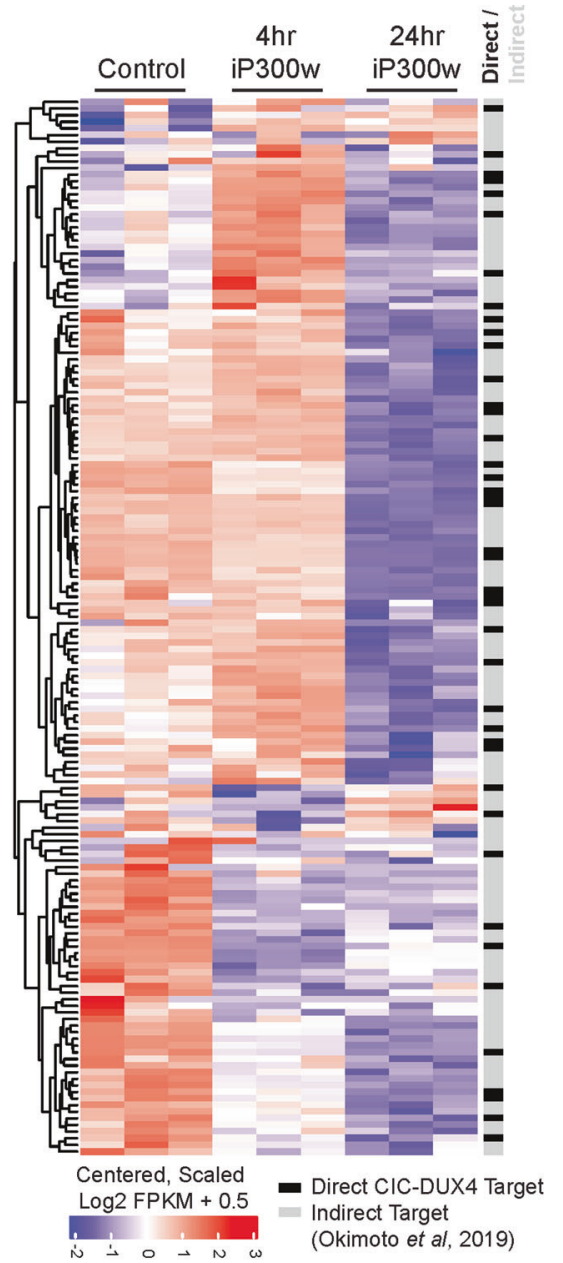

Enriched KEGG Pathways Genes Differentially Expressed at 24hrs

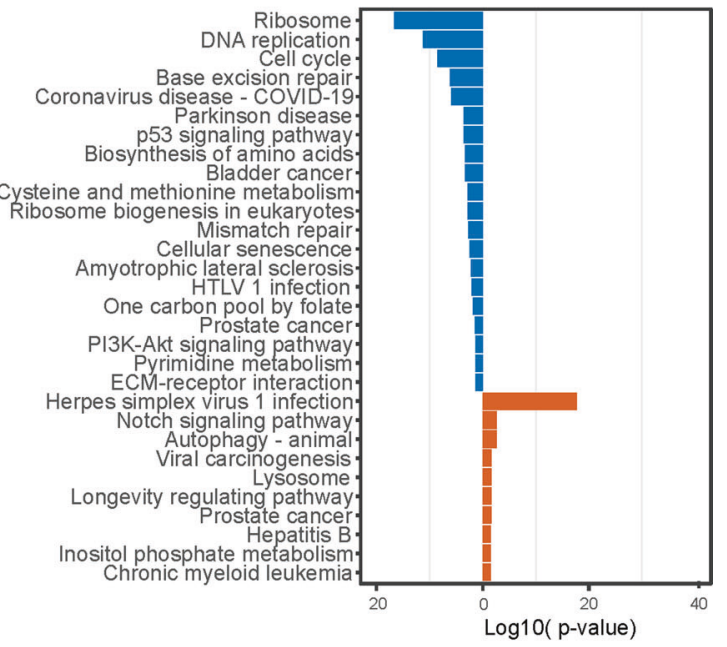

Up Regulated Genes

Fig. 5 iP300w suppresses the CIC-DUX4 target transcriptome. A Scatter plots of $-\log 10$ fold change of the Benjamini-Hochberg adjusted $p$ value versus the observed log 2 fold change in gene expression. The changes with 4 and $24 \mathrm{~h}$ of iP300w treatment are shown on the left and right, respectively. The $y$-axis in each plot has been expanded in the lower panels relative to the upper panels. Points colored in red correspond to the 165 transcripts upregulated by CIC-DUX4 as previously reported [16]. B Heatmap of the log2 padded FPKM values of CICDUX4 targets from Okimoto et al. [16] in NCC-CDS1-X1 cells upon treatment with iP300w. C Enriched KEGG pathways (hypergeometric test, Benjamini-Hochberg adjusted $p$-value $<0.05$ ) of the differentially expressed genes at $4 \mathrm{~h}$ (left) and $24 \mathrm{~h}$ (lower right). The $x$-axis corresponds to the $\log 10$ adjusted $p$-value such that downregulated genes are shown on the negative axis (blue) and upregulated genes (orange) are shown on the positive axis in each plot. 
A
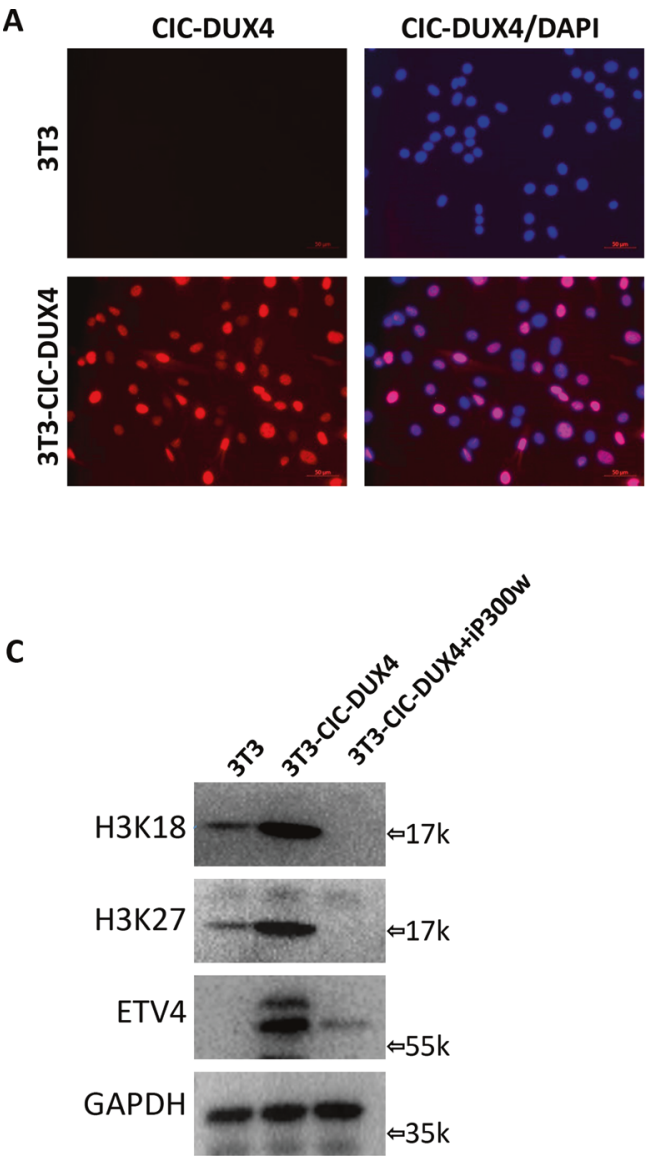

B

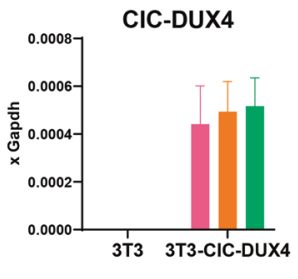

Etv4

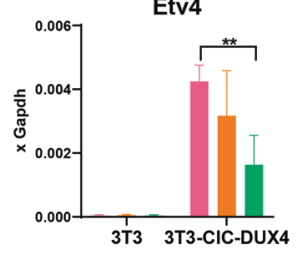

Etv1

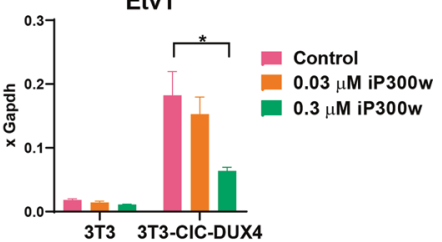

Etv5

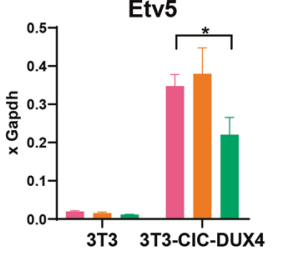

D

NCC-CDS-X1 Kitra-SRC

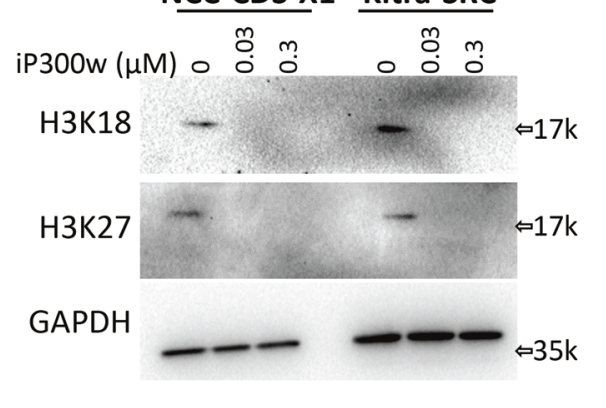

Fig. 6 CIC-DUX4 induces H3 acetylation that is reversible by iP300w. A Immunostaining for CIC-DUX4 in the 3T3-CIC-DUX4 cell line. B RTqPCR for CIC-DUX4 and its target genes in 3T3-CIC-DUX4 cells treated for $18 \mathrm{~h}$ with iP300w. C Western blots for ETV4 and acetylated H3K18 and H3K27 in 3T3-CIC-DUX4 cells treated for $18 \mathrm{~h}$ with iP300w. D Western blots for H3 acetylation markers in CIC-DUX4 sarcoma cell lines treated for $18 \mathrm{~h}$ with iP300w.

Currently, there are four different established CDS cell lines, NCCCDS-X1 and NCC-CDS-X3 which originate from the same patient, NCC-CDS2-C1, and Kitra-SRS [27, 28, 45]. All have been used in multiple screens with known FDA-approved anticancer molecules. Only a handful of drugs, that are not DNA intercalators, like ponatinib, crizotinib, and bortezomib, have shown some degree of effectiveness in vitro $[27,28,45]$. By investigating downstream transcriptional targets of CIC-DUX4, Okimoto et al. identified the CCNE-CDK2 complex as a potential CDS druggable target [16]. Using dinacibil, an approved CDK2 inhibitor, they were able to suppress tumor growth and metastasis in a mouse xenograft model [16]. Applying a similar molecular approach, Nakai et al. found that the viability of Kitra-SRS cells depends on the IGF1/IGF1R pathway, which if it is interrupted with linsitinib, an IGF-1R inhibitor, results in reduced cell proliferation [27]. Both approaches deserve consideration in developing specific therapies for CDS even though they are focused on distant indirect CIC-DUX4 targets. The optimal therapy for CDS would be inactivation of CIC-DUX4, either directly or through targeting of its essential coactivators. Thus specific inhibition of P300/CBP represents a rationally-targeted pharmacological approach to the treatment of CDS.

To this end, we synthesized iP300w, a potent and selective p300/CBP inhibitor, together with several related isomers. iP300w belongs to the same spirocyclic chemical series as A-485, previously shown to be a highly selective catalytic inhibitor of P300/CBP. iP300w is structurally related to A-485, which was previously shown to be a highly selective catalytic inhibitor of P300/CBP [26]. The core of iP300w contains a spirohydantoin with $(\mathrm{S})$ stereochemistry, replaced by a spirooxazolidinedione with (R) stereochemistry in A-485 (Fig. 2A, B). Initial data on earlier compounds in the spirohydantoin series showed that both (S) and (R) forms of the spirocyclic core were tolerated but a $\sim 10$-fold improvement in activity was associated with the (S) form [26]. Interestingly and surprisingly, replacing the spirohydantoin with a spirooxazolidinedione alters the stereochemical preference at this center, with a $\sim 5$-fold improvement in activity associated with $(\mathrm{R})$ stereochemistry $(\mathrm{IC} 50=0.121 \mu \mathrm{M})$, as opposed to (S) $(\mathrm{IC} 50=$ $0.025 \mu \mathrm{M})$ [30]. The preference for a spirooxazolidinedione rather a spirohydantoin in A-485 was attributed to a desire to reduce the number of $\mathrm{H}$-bond donors, to improve permeability and ultimately oral exposure. Recent work on chemical analogs of this series aimed to further improve cellular activity of P300/CBP HAT inhibitors. In this example, researchers opted for lead compounds based on the (S)-spirohydantoin core and achieved higher oral exposure by replacing the urea moiety (present in A-485) with a methylpyrazole [32]. In agreement with Yang et al. [32], we find that the significant improvements in cellular activity can be achieved in A-485-like compounds containing a (S)-spirohydantoin core. Further studies to assess oral exposure and PK/PD of iP300w are warranted to fully assess the potential for clinical translation of this inhibitor.

A-485 was shown to suppress proliferation of a wide spectrum of cancer cell lines, more prominently in those of hematopoietic origin [26]. A-485 has also been found to be effective against high MITF-expressing melanoma cell lines [46] and nuclear protein of the testis (NUT) midline carcinoma [47]. Additionally, A-485 increases the sensitivity of non-small-cell lung carcinoma cells to TRAIL, or A-485 in combination with PD-L1 blockade treatment 
dramatically reduced prostate cancer tumor growth $[48,49]$. The potential to target cancer-associated epigenetic abnormalities is a promising strategy for cancer treatment [50]. Several HDAC inhibitors, including vorinostat, belinostat, and panobinostat are FDA approved for cancer treatment and a dozen more drugs are in the late-stage clinical trials (for review see ref. [51]). However, due to the lack of a potent, selective, and metabolically stable molecule, currently, there is not yet an approved therapeutic HAT inhibitor. While the general efficacy of A-485 against the large number of tumor cell lines is impressive, none of the lines tested involved CIC-DUX4 fusions, where our data shows that P300 inhibition would specifically inactivate the primary oncogenic driver, leading to a specific toxicity in excess of the generic toxicity of inhibiting HAT activity. Furthermore, doses used in these studies are relatively high. Notably, in studies screening FDA approved drugs on CDS cells, screening was performed at $10 \mu \mathrm{M}$ [27], while in the studies above we show that iP300w is effective at $0.003 \mu \mathrm{M}$. In testing against pancreatic and colorectal cancer cell lines expected to have a general P300/CBP dependence, we did not observe toxicities until concentrations of $0.3 \mu \mathrm{M}$ and above, highlighting the extreme sensitivity of CIC-DUX4-induced cancers to iP300w. Furthermore, in our cell-based assays, iP300w was about two orders of magnitude more active than A-485. Considering that these compounds begin to show toxic effects on cells at micromolar concentrations, retaining activity down into the low sub-micromolar range will be essential, making A-485 undesirable in this regard. The greater potency of iP300w is thus critical. Indeed, the lack of toxicity at the effective concentration is highlighted by the fact that our first use of iP300w was against full length DUX4, a toxic protein that causes cell death, and this cell death was prevented by iP300w [25].

As current therapies for CDS are ineffective or very short-lived, with tumors rapidly developing resistance, the ability to inhibit the molecular driver of the disease could provide a transformative therapy for these patients. Based on the in vitro and in vivo data presented here, iP300w is therefore a very promising candidate for targeted therapy in CDS. iP300w will also likely be effective on those cancers for which A-485 has been shown active, and probably at much lower doses. Furthermore, the extreme sensitivity of CDS cell lines to iP300w vis-à-vis other cancer lines highlights the value of specifically targeting the oncogenic driver. It is likely that certain other oncogenic fusion transcription factors carry a similar p300/CBPdependence, and where this occurs, iP300w might be similarly effective. Thus, the continued translational development of iP300w for cancer and CDS in particular is strongly warranted.

\section{METHODS}

\section{Synthesis of iP300w}

See Supplementary Information for synthetic methods. iP300w is now commercially available from Tocris Bioscience.

\section{Cell culture}

All of the basal media were purchased from HyClone, fetal bovine serum (FBS) was from PeakSerum (Ps-FB3, lot 293Q16), and Glutamax (Glu) and Penicillin/ Streptomycin (P/S) were from GIBCO. NCC-CDS-X1 (CIC-DUX4 sarcoma cell line, a generous gift from Tadashi Kondo) cells were cultured in RPMI with 10\% FBS, Glu and P/S, Kitra-SRS (CIC-DUX4 sarcoma cell line, a generous gift from Hidetatsu Otani), 3T3, 293T, and C2C12 cells were cultured in DMEM/10\%FBS/ Glu/P/S. Their identity as CDS cells was confirmed by PCR for CIC-DUX4. The immortalized human myoblast LHCN-M2 cell line was cultured in proliferation medium: F10 supplemented with $20 \% \mathrm{FBS}, 2$-mercaptoethanol $1 \times(\mathrm{GIBCO})$, $10^{-9} \mathrm{M}$ dexamethasone (Sigma), $10 \mathrm{ng} / \mathrm{mL}$ bFGF (Peprotech), and Glu/P/S. All cells were cultured at $37^{\circ} \mathrm{C}$ in a $5 \% \mathrm{CO}_{2}$ atmosphere.

\section{Antibodies, western blot, and immunofluorescence}

For western blot analyses, cells were lysed with RIPA buffer supplemented with protease inhibitor cocktail (Complete, Roche), and proteins were separated on $10 \%$ SDS-PAGE gels, then transferred to PVDF membranes.
Antibodies were diluted in 5\% skim milk in TBST and incubated overnight at $4{ }^{\circ} \mathrm{C}$ or $1 \mathrm{~h}$ at RT. An appropriate secondary HRP conjugated antibody was incubated for $1 \mathrm{~h}$ at RT. Membranes were then washed with TBST, and signal was visualized using Pierce ECL western blotting substrate (Thermo Scientific).

For immunofluorescence, cells cultured in 96-well plates were fixed in 4\% PFA for $10 \mathrm{~min}$, washed twice with PBS, permeabilized with $0.3 \%$ Triton $\mathrm{X}$ for $30 \mathrm{~min}$, and blocked with $3 \% \mathrm{BSA}$ for $1 \mathrm{~h}$ at R/T. Primary antibodies were diluted in $3 \% \mathrm{BSA}$ and incubated $\mathrm{o} / \mathrm{n}$ at $4{ }^{\circ} \mathrm{C}$. An appropriate conjugated secondary antibody was applied for $60 \mathrm{~min}$ at RT. Nuclei were visualized using DAPI (1:5000, Sigma). Antibodies used in the study: GAPDH-HRP $(1: 5000,60004$, Proteintech), rabbit anti-Histone H3K18AC (1:500, ab1191, Abcam), rabbit anti-Histone H3K27Ac (1:500, ab1791, Abcam, lot: GR3297878-1), rabbit anti-ETV4 (1:250, D2720, Santa Cruz), rabbit anti-Ki-67 (dilution 1:250, 9129T, Cell Signaling, lot: 3), rabbit antiDUX4 (1:1000, ab124699, Abcam), secondary Alexa fluor 555 Goat AntiRabbit (1:500, Invitrogen), anti-rabbit CBP (1:1000, 7389S, Cell Signaling, lot: 5), anti-mouse P300 (1:500, 61401, Active Motif, lot\# 31420004), HRP conjugated anti-rabbit (1:5000, 111-035-003, Jackson Immuno Research, lot: 149393), and HRP conjugated anti-mouse: (1:2500, NBP1-75130, Novus, lot 58-173-090418).

\section{Cell viability (ATP) assay}

Cell lines were plated in a 96-well dish $\left(1 \times 10^{5}\right.$ cells/well), and the following day were treated with iP300w or its stereoisomers. ATP assays were performed using CellTiter-Glo ${ }^{\circledR}$ Luminescent Cell Viability Assay (Promega) according to the manufacturer's instructions. Luminescence was analyzed on POLARstar Optima Microplate Reader (BMG Labtech, Offenburg, Germany).

\section{Spheroid assay}

For spheroid formation assays, $2.5 \times 10^{4}$ NCC-CDS-X1 cells were seeded into 96-well plates (96-well Clear Flat Bottom Ultra-Low Attachment Microplate; Corning, Inc., Corning, NY, USA) in MEM/10\%FBS media. Treatment with iP300w was started two days after the plating when the cells formed compact spheres. The size of the spheroids was calculated on $10 \times$ images using ImageJ.

\section{EdU incorporation}

EdU labeling and visualization was done using Click-iT ${ }^{\oplus}$ EdU Flow Cytometry Assay Kit (Thermo Fisher Scientific). Briefly, $1 \times 10^{5}$ NCC-CDS$\mathrm{X} 1$ cells were plated in each well of a 24-well plate. The following day, continual treatment with $0.3 \mu \mathrm{M}$ iP300w was initiated. For the pulse experiment, cells were treated with iP300w for 4 or $24 \mathrm{~h}$ and analyzed $24 \mathrm{~h}$ later. Cells were cultured with EdU $(10 \mathrm{nM})$ in the last $4 \mathrm{~h}$ of the experiment, and samples were prepared for analyses according to the manufacture's instruction. FACS analyses were performed on a BD FACSAria instrument and data was analyzed using FlowJo (BD Biosciences). Experiments were performed on at least three biological replicates.

\section{Mouse tumor formation and evaluation of iP300w in vivo}

Mice were maintained, and in vivo experiments were conducted the University of Minnesota Research Animal Resources facility, under a protocol (1903-36866A) approved by IACUC. Mice were divided into two groups, matching sex and age as closely as possible, and the control vs. experimental group decided by lot. Three-months-old immunodeficient NSG-MDX mice $(n=8)$ were transplanted with $1 \times 10^{7}$ NCC-CDS-X1 cells resuspended in $100 \mu \mathrm{L}$ of a mixture of medium and Matrigel (Corning). Visible tumor masses at the sites of injection were detected on day 9 after transplantation. All of the injected mice developed tumors. At this point, the mice were randomized into two groups, control and iP300w treated, and initial measurement of the tumors was performed. iP300w was initially dissolved in DMSO at $10 \mathrm{mM}$ and then diluted in $100 \mu \mathrm{L}$ PBS. Each mouse received $1.4 \mathrm{mg} / \mathrm{kg}$ iP300w intraperitoneally twice daily or vehicle in the control group. The dose of iP300w was determined based on the effective iP300w concentration on CDS sarcomas in vitro $(1 \mu \mathrm{M})$ and from our previous experience with iP300w and DUX4 inactivation in the iDUX4pA mouse, an FSHD animal model [25]. Tumor size was recorded every 4 days and the volume was calculated using the formula (length $\times$ width $^{2}$ )/2. Mice were identified by number. Investigator was blind to the status of the particular mouse during the dissection, weighing, and photographing of the tumors. 


\section{Generation of CIC-DUX4 expression cell lines}

Viral supernatants were produced in 293T cells. For transducing mouse cells (3T3 and C2C12), the CIC-DUX4 expression vector [17] was packaged with $\mathrm{pCL}-$ Eco, and pVSV-G/pCMVgp were used for infecting human cells (LHCN-M2). Packaging cells were transfected with DNA plasmids using TransIT-LT1 reagent (Mirus). Viral supernatant was collected at 48 and $72 \mathrm{~h}$ of post-transfection and applied to the cells. Two days of post-infection GFP positive cells were sorted using a BD FACSAria II. Established cell lines were tested for CIC-DUX4 expression by immunofluorescence and RT-qPCR.

\section{RNA isolation, quantitative real-time RT-PCR (RT-qPCR), and RNAseq}

RNA was extracted using an RNA extraction kit (Zymo) and cDNA was made using $0.5 \mu \mathrm{g}$ total RNA with oligo-dT primer and Verso CDNA Synthesis Kit (Thermo Scientific) following the manufacturer's instructions. qPCRs were performed by using Premix Ex Taq (Probe qPCR, Takara) or SYBR-green. Probes and primer sets used in this study are presented in Supplementary Table 2. Gene expression levels were normalized to that of $G A P D H$ or B2M and analyzed with 7500 System Software using the $\triangle C T$ method (Applied Biosystems).

RNA-seq library preparation was done with $500 \mathrm{ng}$ total RNA from NCCCDS-X1 cells treated for 4 or $24 \mathrm{~h}$ with iP300w $(0.3 \mu \mathrm{M})$ using the Swift Rapid RNA Library Kit (SwiftBioscience). Thirty-six base paired-end sequencing was performed on an Illumina NextSeq instrument at the University of Minnesota Genomics Center.

\section{RNA interference}

NCC-CDS-X1 and Kitra-SRS cells were seeded into 96 -well plates $\left(5 \times 10^{4}\right.$ / well) for cell viability evaluation or a 24 -well plate $\left(1.5 \times 10^{5} /\right.$ well) for RNA isolation. The following day, $50 \mathrm{nM}$ siRNA for human P300 (L-003486-000005), CREBBP (L-003477-00-0005), or scrambled control (SMARTpool, Dharmacon) were transfected using Lipofectamine RNAiMAX (Invitrogen). RNA was isolated $48 \mathrm{~h}$ of post-transfection and the effect on cell viability was analyzed at 72 and $96 \mathrm{~h}$ of post-transfection.

\section{Bioinformatics}

Paired-end Illumina sequencing reads were trimmed with TrimGalore (0.6.0) and transcript abundance was quantified using the human Gencode annotations (v34) using Salmon ( $v$ 1.2.1) with the GC-bias correction option. Counts were imported into $R$ ( $v$ 4.0.2) using tximeta ( $v$ 1.6.3). Differentially expressed genes were identified with DESeq2 $(v$ 1.28.1) and figures were made with the ComplexHeatmap (v 2.4.3), cluster Profiler ( $v$ 3.16.1) and ggplot2 ( $v$ 3.3.2) $R$ packages. Sequencing reads and processed data have been deposited into GEO under the accession number GSE165729.

\section{Statistics}

Graphpad Prism software was used for statistical analyses of the data, except when indicated. The sample size was chosen according to prior experience with the assays used to ensure adequate statistical power. Variance was similar within groups. Differences between groups were evaluated by one-way or two-way analysis of variance (ANOVA) followed by Tukey's post-hoc tests. Differences were considered significant at $p$ values of 0.05 or lower.

\section{REFERENCES}

1. Italiano A, Sung YS, Zhang L, Singer S, Maki RG, Coindre JM, et al. High prevalence of $\mathrm{CIC}$ fusion with double-homeobox (DUX4) transcription factors in EWSR1negative undifferentiated small blue round cell sarcomas. Genes Chromosomes Cancer. 2012;51:207-18.

2. Hung YP, Fletcher CD, Hornick JL. Evaluation of ETV4 and WT1 expression in CICrearranged sarcomas and histologic mimics. Mod Pathol. 2016;29:1324-34.

3. Gambarotti M, Benini S, Gamberi G, Cocchi S, Palmerini E, Sbaraglia M, et al. CICDUX4 fusion-positive round-cell sarcomas of soft tissue and bone: a singleinstitution morphological and molecular analysis of seven cases. Histopathology. 2016;69:624-34.

4. Donahue JE, Yakirevich E, Zhong S, Treaba DO, Lakis NS, Ali SM, et al. Primary spinal epidural CIC-DUX4 undifferentiated sarcoma in a child. Pediatr Dev Pathol. 2018;21:411-7.

5. Ricker CA, Berlow NE, Crawford KA, Georgopapadakos T, Huelskamp AN, Woods $A D$, et al. Undifferentiated small round cell sarcoma in a young male: a case report. Mol Case Stud. 2020;6:a004812.
6. Choi EY, Thomas DG, McHugh JB, Patel RM, Roulston D, Schuetze SM, et al. Undifferentiated small round cell sarcoma with $\mathrm{t}(4 ; 19)(\mathrm{q} 35 ; \mathrm{q} 13.1)$ CIC-DUX4 fusion: a novel highly aggressive soft tissue tumor with distinctive histopathology. Am J Surg Pathol. 2013;37:1379-86.

7. Graham C, Chilton-MacNeill S, Zielenska M, Somers GR. The CIC-DUX4 fusion transcript is present in a subgroup of pediatric primitive round cell sarcomas. Hum Pathol. 2012;43:180-9.

8. Kawamura-Saito M, Yamazaki Y, Kaneko K, Kawaguchi N, Kanda H, Mukai H, et al. Fusion between CIC and DUX4 up-regulates PEA3 family genes in Ewing-like sarcomas with $\mathrm{t}(4 ; 19)(\mathrm{q} 35 ; \mathrm{q} 13)$ translocation. Hum Mol Genet. 2006;15:2125-37.

9. Yoshida A, Goto K, Kodaira M, Kobayashi E, Kawamoto H, Mori T, et al. CICrearranged sarcomas: a study of 20 cases and comparisons with Ewing sarcomas. Am J Surg Pathol. 2016;40:313-23.

10. Le Guellec S, Velasco V, Pérot G, Watson S, Tirode F, Coindre JM. ETV4 is a useful marker for the diagnosis of $\mathrm{ClC}$-rearranged undifferentiated round-cell sarcomas: a study of 127 cases including mimicking lesions. Mod Pathol. 2016;29:1523-31.

11. Haidar A, Arekapudi S, DeMattia F, Abu-Isa E, Kraut M. High-grade undifferentiated small round cell sarcoma with $t(4 ; 19)(q 35 ; q 13.1)$ CIC-DUX4 fusion: emerging entities of soft tissue tumors with unique histopathologic features-a case report and literature review. Am J Case Rep. 2015;16:87-94.

12. Lyle R, Wright TJ, Clark LN, Hewitt JE. The FSHD-associated repeat, D4Z4, is a member of a dispersed family of homeobox-containing repeats, subsets of which are clustered on the short arms of the acrocentric chromosomes. Genomics. 1995;28:389-97.

13. Gabriëls J, Beckers MC, Ding H, De Vriese A, Plaisance S, van der Maarel SM, et al. Nucleotide sequence of the partially deleted D4Z4 locus in a patient with FSHD identifies a putative gene within each 3.3 kb element. Gene. 1999;236:25-32.

14. Bosnakovski D, Toso EA, Hartweck LM, Magli A, Lee HA, Thompson ER, et al. The DUX4 homeodomains mediate inhibition of myogenesis and are functionally exchangeable with the Pax7 homeodomain. J Cell Sci. 2017;130:3685-97.

15. Choi SH, Gearhart MD, Cui Z, Bosnakovski D, Kim M, Schennum N, et al. DUX4 recruits p300/CBP through its C-terminus and induces global H3K27 acetylation changes. Nucleic Acids Res. 2016;44:5161-73.

16. Okimoto RA, Wu W, Nanjo S, Olivas V, Lin YK, Ponce RK, et al. CIC-DUX4 oncoprotein drives sarcoma metastasis and tumorigenesis via distinct regulatory programs. J Clin Invest. 2019;129:3401-6.

17. Yoshimoto T, Tanaka M, Homme M, Yamazaki Y, Takazawa Y, Antonescu CR, et al. CIC-DUX4 induces small round cell sarcomas distinct from Ewing sarcoma. Cancer Res. 2017;77:2927-37.

18. Hendrickson PG, Doráis JA, Grow EJ, Whiddon JL, Lim JW, Wike CL, et al. Conserved roles of mouse DUX and human DUX4 in activating cleavage-stage genes and MERVL/HERVL retrotransposons. Nat Genet. 2017;49:925-34.

19. Chen Z, Zhang Y. Loss of DUX causes minor defects in zygotic genome activation and is compatible with mouse development. Nat Genet. 2019;51:947-51.

20. Bosnakovski D, Gearhart MD, Ho Choi S, Kyba M. Dux facilitates post-implantation development, but is not essential for zygotic genome activation. Biol Reprod. 2021;104:83-93.

21. Lemmers RJLF, van der Vliet PJ, Klooster R, Sacconi S, Camano P, Dauwerse JG, et al. A unifying genetic model for facioscapulohumeral muscular dystrophy. Science. 2010;329:1650-3.

22. Bosnakovski D, Xu Z, Ji Gang E, Galindo CL, Liu M, Simsek T, et al. An isogenetic myoblast expression screen identifies DUX4-mediated FSHD-associated molecular pathologies. EMBO J. 2008;27:2766-79.

23. Dixit M, Ansseau E, Tassin A, Winokur S, Shi R, Qian H, et al. DUX4, a candidate gene of facioscapulohumeral muscular dystrophy, encodes a transcriptional activator of PITX1. Proc Natl Acad Sci USA. 2007;104:18157-62.

24. Bosnakovski D, Gearhart MD, Toso EA, Ener ET, Choi SH, Kyba M. Low level DUX4 expression disrupts myogenesis through deregulation of myogenic gene expression. Sci Rep. 2018;8:16957.

25. Bosnakovski D, da Silva MT, Sunny ST, Ener ET, Toso EA, Yuan C, et al. A novel P300 inhibitor reverses DUX4-mediated global histone $\mathrm{H} 3$ hyperacetylation, target gene expression, and cell death. Sci Adv. 2019;5:eaaw7781.

26. Lasko LM, Jakob CG, Edalji RP, Qiu W, Montgomery D, Digiammarino EL, et al. Discovery of a selective catalytic p300/CBP inhibitor that targets lineage-specific tumours. Nature. 2017;550:128-32.

27. Nakai $\mathrm{S}$, Yamada $\mathrm{S}$, Outani $\mathrm{H}, \mathrm{Nakai} T$, Yasuda $\mathrm{N}$, Mae $\mathrm{H}$, et al. Establishment of a novel human CIC-DUX4 sarcoma cell line, Kitra-SRS, with autocrine IGF-1R activation and metastatic potential to the lungs. Sci Rep. 2019;9:15812.

28. Oyama R, Takahashi M, Yoshida A, Sakumoto M, Takai Y, Kito F, et al. Generation of novel patient-derived CIC-DUX4 sarcoma xenografts and cell lines. Sci Rep. 2017;7:4712.

29. Specht K, Sung YS, Zhang L, Richter GH, Fletcher CD, Antonescu CR. Distinct transcriptional signature and immunoprofile of CIC-DUX4 fusion-positive round cell tumors compared to EWSR1-rearranged Ewing sarcomas: further evidence toward distinct pathologic entities. Genes Chromosomes Cancer. 2014;53:622-33. 
30. Michaelides MR, Kluge A, Patane M, Van Drie JH, Wang C, Hansen TM, et al. Discovery of Spiro oxazolidinediones as selective, orally bioavailable inhibitors of p300/CBP histone acetyltransferases. ACS Med Chem Lett. 2018;9:28-33.

31. Wilson JE, Patel G, Patel C, Brucelle F, Huhn A, Gardberg AS, et al. Discovery of CPI-1612: a potent, selective, and orally bioavailable EP300/CBP histone acetyltransferase Inhibitor. ACS Med Chem Lett. 2020;11:1324-9.

32. Yang Y, Zhang R, Li Z, Mei L, Wan S, Ding H, et al. Discovery of highly potent, selective, and orally efficacious p300/CBP histone acetyltransferases inhibitors. J Med Chem. 2020;63:1337-60.

33. Iyer NG, Chin SF, Ozdag H, Daigo Y, Hu DE, Cariati M, et al. p300 regulates p53dependent apoptosis after DNA damage in colorectal cancer cells by modulation of PUMA/p21 levels. Proc Natl Acad Sci USA. 2004;101:7386-91.

34. Paladino D, Yue $P$, Furuya $H$, Acoba J, Rosser CJ, Turkson J. A novel nuclear Src and p300 signaling axis controls migratory and invasive behavior in pancreatic cancer. Oncotarget. 2016;7:7253-67.

35. Raisner R, Kharbanda S, Jin L, Jeng E, Chan E, Merchant M, et al. Enhancer activity requires CBP/P300 bromodomain-dependent histone H3K27 acetylation. Cell Rep. 2018;24:1722-9.

36. Visel A, Blow MJ, Li Z, Zhang T, Akiyama JA, Holt A, et al. ChIP-seq accurately predicts tissue-specific activity of enhancers. Nature. 2009;457:854-8.

37. Jin Q, Yu LR, Wang L, Zhang Z, Kasper LH, Lee JE, et al. Distinct roles of GCN5/ PCAF-mediated H3K9ac and CBP/p300-mediated H3K18/27ac in nuclear receptor transactivation. EMBO J. 2011;30:249-62.

38. Liu X, Wang L, Zhao K, Thompson PR, Hwang Y, Marmorstein R, et al. The structural basis of protein acetylation by the p300/CBP transcriptional coactivator. Nature. 2008;451:846-50.

39. Ogryzko VV, Schiltz RL, Russanova V, Howard BH, Nakatani Y. The transcriptional coactivators p300 and CBP are histone acetyltransferases. Cell. 1996;87:953-9.

40. Goodman RH, Smolik S. CBP/p300 in cell growth, transformation, and development. Genes Dev. 2000;14:1553-77.

41. Iyer NG, Ozdag H, Caldas C. p300/CBP and cancer. Oncogene. 2004;23:4225-31.

42. Pao GM, Janknecht $R$, Ruffner $H$, Hunter T, Verma IM. CBP/p300 interact with and function as transcriptional coactivators of BRCA1. Proc Natl Acad Sci USA. 2000;97:1020-5

43. Vervoorts J, Lüscher-Firzlaff JM, Rottmann S, Lilischkis R, Walsemann G, Dohmann $\mathrm{K}$, et al. Stimulation of c-MYC transcriptional activity and acetylation by recruitment of the cofactor CBP. EMBO Rep. 2003;4:484-90.

44. Zhong J, Ding L, Bohrer LR, Pan Y, Liu P, Zhang J, et al. p300 acetyltransferase regulates androgen receptor degradation and PTEN-deficient prostate tumorigenesis. Cancer Res. 2014;74:1870-80.

45. Yoshimatsu Y, Noguchi R, Tsuchiya R, Kito F, Sei A, Sugaya J, et al. Establishment and characterization of NCC-CDS2-C1: a novel patient-derived cell line of CICDUX4 sarcoma. Hum Cell. 2020;33:427-36.

46. Wang $R$, He $Y$, Robinson V, Yang Z, Hessler $P$, Lasko LM, et al. Targeting lineagespecific MITF pathway in human melanoma cell lines by $A-485$, the selective small-molecule inhibitor of p300/CBP. Mol Cancer Ther. 2018;17:2543-50.

47. Zhang $X$, Zegar T, Lucas A, Morrison-Smith C, Knox T, French CA, et al. Therapeutic targeting of p300/CBP HAT domain for the treatment of NUT midline carcinoma. Oncogene. 2020;39:4770-9.

48. Zhang B, Chen D, Liu B, Dekker FJ, Quax WJ. A novel histone acetyltransferase inhibitor A485 improves sensitivity of non-small-cell lung carcinoma cells to TRAIL. Biochem Pharm. 2020;175:113914.

49. Liu J, He D, Cheng L, Huang C, Zhang Y, Rao X, et al. p300/CBP inhibition enhances the efficacy of programmed death-ligand 1 blockade treatment in prostate cancer. Oncogene. 2020;39:3939-51.

50. Cheng Y, He C, Wang M, Ma X, Mo F, Yang S, et al. Targeting epigenetic regulators for cancer therapy: mechanisms and advances in clinical trials. Signal Transduct Target Ther. 2019;4:62.

51. Li Y, Seto E. HDACs and HDAC inhibitors in cancer development and therapy. Cold Spring Harb Perspect Med. 2016;6:a026831.

\section{ACKNOWLEDGEMENTS}

This work was supported by grants from the Children's Cancer Research Fund (Research Grant Award 2020 and Project Grant 2021), and the National Institute of Arthritis and Musculoskeletal and Skin Diseases (R01 AR055685). The authors would like to acknowledge Dr Michael Hall and Dr Michael Probert, Indicatrix Crystallography, for crystallisation and single crystal x-ray diffraction measurements Madison Douglas, Varun Goal, Johannes Weiblen, and Ben Mai for assistance with data analysis and animal maintenance; Takuro Nakamura, Japanese Foundation for Cancer Research for providing the DUX4-CIC viral expression vector; and Tadashi Kondo, National Cancer Centre, Japan; Hidetatsu Otani, Osaka University, Japan Michael Verneris, University of Colorado; and Masato Yamamoto and Eric Hendrickson, University of Minnesota for provision of cell lines.

\section{AUTHOR CONTRIBUTIONS}

DB, ETE, CAP, NCX, EAT, MSC, KAK, HJM, GPM investigation. DB, MDG, MSC, KAK, HJM, GPM, MK analysis. MDG, bioinformatics. MK and DB designed and supervised the research, and DB, MDG, HJM, GPM and MK prepared the manuscript.

\section{ETHICAL APPROVAL}

Animals were maintained under protocol 1708-35046A approved by the University of Minnesota IACUC. Animals were euthanized by cervical dislocation.

\section{COMPETING INTERESTS}

The authors declare no competing interests.

\section{ADDITIONAL INFORMATION}

Supplementary information The online version contains supplementary material available at https://doi.org/10.1038/s41389-021-00357-4.

Correspondence and requests for materials should be addressed to Darko Bosnakovski or Michael Kyba.

Reprints and permission information is available at http://www.nature.com/ reprints

Publisher's note Springer Nature remains neutral with regard to jurisdictional claims in published maps and institutional affiliations.

Open Access This article is licensed under a Creative Commons Attribution 4.0 International License, which permits use, sharing, adaptation, distribution and reproduction in any medium or format, as long as you give appropriate credit to the original author(s) and the source, provide a link to the Creative Commons license, and indicate if changes were made. The images or other third party material in this article are included in the article's Creative Commons license, unless indicated otherwise in a credit line to the material. If material is not included in the article's Creative Commons license and your intended use is not permitted by statutory regulation or exceeds the permitted use, you will need to obtain permission directly from the copyright holder. To view a copy of this license, visit http://creativecommons. org/licenses/by/4.0/.

(c) The Author(s) 2021 